\title{
New Potential Demulsifiers Obtained by Processing Gossypol Resin
}

\author{
Nurlybek Shyrynbekuly Otarbaev ${ }^{1}$, Vladimir Mikhailovich Kapustin ${ }^{2}$, Kazim Sadykovich Nadirov ${ }^{1}$, \\ Gulmira Zhankabylovna Bimbetova ${ }^{1}$, Manap Kurmanbekovich Zhantasov ${ }^{1}$, and Rashid Kazimovich \\ Nadirov ${ }^{3, *}$
}

${ }^{1}$ M.O. Auezov South Kazakhstan State University, Avenue Tauke Khan 5, 160012, Shymkent, Republic of Kazakhstan

${ }^{2}$ Gubkin Russian State University of Oil and Gas (National Research University), 65 Leninsky Ave,

Moscow 119991, Russian Federation

${ }^{3}$ Al-Farabi Kazakh National University, 71 Al-Farabi Ave, Almaty 050040, Republic of Kazakhstan

\section{*Corresponding author:}

email: nadirov.rashid@gmail.com

Received: September 9, 2018

Accepted: March 20, 2019

DOI: $10.22146 /$ ijc.38671

\begin{abstract}
Water contained in crude oil, forms so-called water-in-oil emulsions, the presence of which negatively affects the transportation and processing of oil. Demulsifiers are the special mixtures that are used to remove water from emulsions. The present paper is devoted to obtaining the demulsifiers by catalytic acid esterification of fatty acids mixture extracted from gossypol resin with isopropanol. Fourteen mixtures, containing mainly fatty acids and their ethers, were obtained and tested for demulsifying performance by using the bottle test. The relationship of the following values with the demulsibility of final mixtures was determined: the conditions of fatty acids esterification, the content of fatty acids in the demulsifier, the relative solubility number of the demulsifier, the toluene/water dynamic interfacial tension. The following conditions of fatty acids mixture esterification provided $64.8 \%$ of water removal at the dosage of 20 ppm of demulsifier: $385 \mathrm{~K} ; 4 \mathrm{~h} ; \mathrm{H}_{2} \mathrm{SO}_{4} /$ fatty acids mixture ratio $2.5 \mathrm{wt} \%$.
\end{abstract}

Keywords: gossypol resin; fatty acids esterification; water-in-oil emulsion; demulsifier

\section{- INTRODUCTION}

Generally, crude oil contains emulsified water. Since both transportation and processing of so-called water-inoil emulsions have a negative impact on production costs, the emulsion should be broken down in order to remove water from the oil. Demulsification techniques can be classified into three groups, i.e., chemical, biological, and physical processing [1]. Chemical demulsification is recognized as the most widely used method of treating water-in-oil emulsions and includes introducing additives into emulsion [2-4]. These additives, called demulsifiers, destroy the emulsion and lead to the separation of water from oil. Demulsifiers are reagents from several chemical substances (surfactants, modifiers, and solvents), developed based on the properties and components of the emulsion being separated. Thousands of patents and papers are devoted to using chemical substances and compositions for the destabilization of water-in-oil emulsion in petroleum industry [1,5-15].

Fatty acids and their ethers refer to surfactants and are often part of demulsifiers [16-19]. At the same time, fatty acids are contained in by-products in the process of obtaining edible oils [20-22]. These acids can be converted to the corresponding ethers, mainly to methyl ones [23-24].

Gossypol resin, being a by-product of cottonseed oil processing, contains about 52-64 wt.\% of crude fatty acids and their derivatives [25]. The lack of widespread use in the industry makes gossypol resin a quite cheap and affordable material. Thus, gossypol resin can be considered as a potential raw material for the production of demulsifiers. The possibility of obtaining demulsifiers via the process of oxy-ethylation of fatty acids of gossypol resin has been previously demonstrated by other researchers [26]. However, it was mainly focused on finding the relationship between the oxy-ethylation 
conditions and the demulsifier composition, while the demulsifier properties were not described.

In the present work, we attempted to prepare the demulsifiers by acid catalytic etherification of fatty acids mixture extracted from gossypol resin by using isopropanol. The process of esterification of fatty acids is chiefly of interest from the point of view of obtaining biodiesel and has been sufficiently well studied [27]. However, the relationship between the conditions of gossypol resin's fatty acids esterification with isopropanol and the demulsifying ability of the products obtained was not previously investigated. This fact encouraged us to investigate the possibility of obtaining new potential demulsifiers from gossypol resin.

\section{- EXPERIMENTAL SECTION}

\section{Materials}

The gossypol resin was obtained from Shymkentmay JSC which is located in Shymkent (South Kazakhstan). The composition of the resin, determined by high-performance liquid chromatography, was the following, wt.\%: fatty acids 55.2, other 44.8 .

Crude oil obtained from the Kumkol field was used for the experiments. The composition of the oil was determined using high-performance liquid chromatography (Varian Pro). The crude oil sample showed the following characteristics: density $\left(20{ }^{\circ} \mathrm{C}\right)$ $813 \mathrm{~kg} / \mathrm{m}^{3}$; kinematic viscosity $\left(20^{\circ} \mathrm{C}\right) 12.1 \mathrm{~mm}^{2} \times \mathrm{s}^{-1}$; ${ }^{\circ} \mathrm{API}$ 42.5; water content $8.52 \mathrm{vol} . \%$; salt content $98 \mathrm{~kg} \times \mathrm{m}^{-3}$; aromatics content $6.8 \mathrm{wt} . \%$; sulfur content $0.24 \mathrm{wt} . \%$; paraffin content $11.1 \mathrm{wt} . \%$; asphaltenes content $0.46 \mathrm{wt} . \%$; resins content $5.19 \mathrm{wt} . \%$.

Sulfuric acid and sodium hydroxide were purchased from Merck. Isopropanol, petrol, toluene, m-xylene, and ethylene glycol dimethyl ether were purchased from Sigma-Aldrich and were used as received. Dissolvan 4411 demulsifier was purchased from Krezol Ltd. This demulsifier is an ethylene/propylene oxide dissolved in methanol. Some key characteristics of Dissolvan 4411 are as follows: density at $20{ }^{\circ} \mathrm{C}$ (ASTM D 1475/DIN 51757)

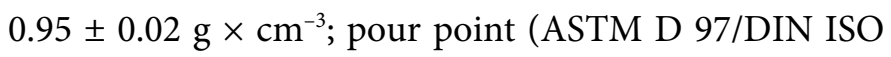
$3016)-36^{\circ} \mathrm{C}$; viscosity at $20^{\circ} \mathrm{C}$ (ASTM D 445/DIN 53015) $25 \mathrm{mPa} \times \mathrm{s}$.

\section{Procedure}

\section{Extraction of free fatty acids from gossypol resin}

Twenty grams of gossypol resin and $200 \mathrm{~mL}$ of petrol (Sigma-Aldrich) were pre-heated to $28-30{ }^{\circ} \mathrm{C}$, then thoroughly mixed for $5 \mathrm{~min}$ in a $250 \mathrm{~mL}$ flask. The solid part was then filtered, and the solvent was evaporated under the vacuum. The residue was dark brown viscous liquid and hereinafter is called free fatty acids mixture (FFAM). The mass of the mixture was $8.65 \mathrm{~g}$. The composition of the FFAM was determined by high-performance liquid chromatography (Varian Pro).

\section{Obtaining demulsifiers}

Eighteen grams of FFAM and a pre-determined amount of $80 \% \mathrm{H}_{2} \mathrm{SO}_{4}$ were added to $50 \mathrm{~mL}$ of isopropanol and formed mixture was heated in an autoclave (RVD-2-150, Ukraine) for $1-5 \mathrm{~h}$ at $355-400 \mathrm{~K}$ and $0.8-1.0 \mathrm{MPa}$. Then, the relatively low boiling fraction of the mixture was distilled off by heating the resulting mixture at $105 \pm 2{ }^{\circ} \mathrm{C}$ under the ambient pressure for $1 \mathrm{~h}$. The residue was neutralized by $\mathrm{NaOH}$ solution until $\mathrm{pH}=7.0-7.5$. The obtained products (114), which were viscous brown liquid with a specific odor, were called as demulsifiers hereinafter in this paper. The chemical composition of all the 14 demulsifiers was determined by high-performance liquid chromatography (see Tables 2 and 3 ).

\section{Preparation of water-in-oil emulsion}

Previously, the oil sample was centrifuged in order to remove all the solid impurities, and pre-heated to $70{ }^{\circ} \mathrm{C}$. Then, the predetermined volume of distilled water was mixed with $100 \mathrm{~mL}$ of the oil by using a mechanical stirrer (Mslos18-23), at 2800-3000 rpm for $10 \mathrm{~min}$, to obtain water-in-oil emulsions with a water content of $20 \mathrm{wt} . \%$, taking into account the water content in the crude oil sample. $\mathrm{pH}$ value of the emulsion was adjusted by using $\mathrm{NaOH}$ to get $\mathrm{pH}=7.0$.

\section{Demulsification tests}

Demulsification tests were conducted using a bottle test [28]. According to the procedure, $100 \mathrm{~mL}$ of the emulsion was transferred to graduated glass bottles of the volume of $150 \mathrm{~mL}$. The predetermined amounts of demulsifier were added to the emulsion using a 
micropipette. The bottles were shaken for 6-8 $\mathrm{min}$ to thoroughly mix the demulsifier and the water-in-oil emulsion, and the mixture was later transferred to the incubator (BioSan Thermostat Combitherm-2 CH 3-150) in which a temperature of $70{ }^{\circ} \mathrm{C}$ was maintained. The position of the oil/emulsion interface was used for monitoring the process of phases separation. Demulsifier performance was measured by the percentage of water separated from the oil, which is calculated as:

water removal $(\mathrm{wt} . \%)=\frac{\mathrm{C}_{0}-\mathrm{C}}{\mathrm{C}_{0}}$

where $\mathrm{C}_{0}$ is the original water content before settling, and $\mathrm{C}$ is the water content after settling.

Parallel experiments were performed until reproducibility of $\pm 0.1 \%$ was achieved.

\section{Determination of water content}

Modified ASTM D4007-02 standard method was used for the determination of water content in crude oil. The oil sample was mixed with $\mathrm{m}$-xylene (1:1 vol.), then the commercial demulsifier Dissolvan 4411 was added to the mixture $(20 \mathrm{ppm})$. The resulting mixture was placed into the cone-shaped centrifuge tubes and centrifuged by using HettikMikro 220 R Centrifuge at $2100 \mathrm{rpm}$ for 15 min. The volume of the separated water, as well as the sediment layer at the bottom of the tube, were measured to determine the water content in the oil sample.

\section{Determination of relative solubility number (RSN)}

The values of RSN for the demulsifiers were found according to the procedures suggested in previous studies [29]. One gram of tested demulsifier was thoroughly mixed with $15 \mathrm{~mL}$ of toluene and ethylene glycol dimethyl ether. The resultant solution was titrated with distilled water until the solution has acquired constant turbidity. The volume of water $(\mathrm{mL})$ was further used as RSN number.

\section{Determination of interfacial tension}

The interfacial tension as a function of the concentration of demulsifier in the model system «toluene-water» at $25{ }^{\circ} \mathrm{C}$ using the Wilhelmy plate method with a Kruss K-20 tensiometer. The predetermined amount of demulsifier was initially dissolved in toluene to obtain the desired concentration. Reproducibility of measurements was within $0.1 \mathrm{mN} / \mathrm{m}$. $\mathrm{pH}$ value was adjusted by using $\mathrm{NaOH}$ to get $\mathrm{pH}=7.0$.

\section{- RESULTS AND DISCUSSION}

\section{Free Fatty Acids Mixture Recovery from the Gossypol Resin}

The composition of the FFAM is presented in Table 1.

It is shown that $93.8 \%$ of the FFAM isolated from gossypol resin consists of free fatty acids, while the content of unsaturated fatty acids in the mixture was about $75 \mathrm{wt} . \%$. The fatty acids recovery from gossypol resin was calculated as follows:

FA Recovery $=\frac{8.65 \times 0.938}{20 \times 0.552} \times 100 \%=73.49 \%$

where $8.65 \mathrm{~g}$ is the mass of FFAM, 0.938 is the mass fraction of fatty acids in the FFAM, $20 \mathrm{~g}$ is the mass of gossypol resin, and 0.552 is the mass fraction of free fatty acids in gossypol resin.

\section{Demulsifiers Testing}

Water removal from the emulsion at demulsifier dosage of $20 \mathrm{ppm}$ is presented in Table 2, for all the 14 synthesized demulsifiers; the mixture of water-in-oil emulsion and demulsifier was allowed to stand for $2 \mathrm{~h}$ to ensure that the maximum possible removal of water was achieved.

It can be noted that samples 8 and 10 showed a sufficiently high demulsibility, while samples 1 and 9 indicated a very low one. Further studies were aimed at finding the relationship between the composition and properties of demulsifiers and their demulsifying ability.

Table 1. The composition of the fatty acids mixture

\begin{tabular}{ll}
\hline Component & wt.\% \\
\hline Linoleic acid & 31.1 \\
Linolenic acid & 24.3 \\
Oleic acid & 19.5 \\
Palmitic acid & 14.5 \\
Stearic acid & 2.1 \\
Other acids & 2.3 \\
Other compounds & 6.2 \\
\hline
\end{tabular}


Table 2. Effect of conditions of obtaining demulsifiers on their ability to extract water from the emulsion (duration of demulsification $2 \mathrm{~h}$; demulsifier dosage $20 \mathrm{ppm}$ )

\begin{tabular}{ccccc}
\hline $\begin{array}{c}\text { No of } \\
\text { demulsifier }\end{array}$ & $\begin{array}{c}\text { Temperature of } \\
\text { esterification process }(\mathrm{K})\end{array}$ & $\begin{array}{c}\text { Process duration } \\
(\mathrm{h})\end{array}$ & $\begin{array}{c}\mathrm{H}_{2} \mathrm{SO}_{4} / \mathrm{FFAM} \text { ratio } \\
(\mathrm{wt} . \%)\end{array}$ & $\begin{array}{c}\text { Water removal } \\
\%\end{array}$ \\
\hline 1 & 355 & 2 & 1.5 & 2.6 \\
2 & 385 & 2 & 1.5 & 24.8 \\
3 & 355 & 4 & 1.5 & 15.9 \\
4 & 385 & 4 & 1.5 & 39.2 \\
5 & 355 & 2 & 2.5 & 14.4 \\
6 & 385 & 2 & 2.5 & 26.1 \\
7 & 355 & 4 & 2.5 & 28.5 \\
8 & 385 & 4 & 2.5 & 64.8 \\
9 & 340 & 3 & 2 & 3.4 \\
10 & 400 & 3 & 2 & 61.7 \\
11 & 370 & 1 & 2 & 31.6 \\
12 & 370 & 5 & 2 & 28.0 \\
13 & 370 & 3 & 1 & 12.9 \\
14 & 370 & 3 & 3 & 18.7 \\
\hline
\end{tabular}

Table 3. The composition of demulsifiers

\begin{tabular}{ccccc}
\hline No of & \multicolumn{4}{c}{ The content of demulsifier, wt.\% } \\
\cline { 2 - 5 } demulsifier & Ethers of fatty acids & Fatty acids & $\mathrm{Na}_{2} \mathrm{SO}_{4}$ & Other compounds \\
\hline 1 & 3.7 & 87.5 & 1.4 & 7.4 \\
2 & 11.5 & 79.5 & 1.3 & 7.7 \\
3 & 7.4 & 83.6 & 1.4 & 7.6 \\
4 & 29.8 & 61 & 1.4 & 7.8 \\
5 & 6 & 83.2 & 2.3 & 8.5 \\
6 & 14.9 & 74.4 & 2.2 & 8.5 \\
7 & 8.7 & 80.3 & 2.3 & 8.7 \\
8 & 49.3 & 40.2 & 2.5 & 8.0 \\
9 & 1.5 & 89 & 2 & 7.5 \\
10 & 51.4 & 38.1 & 1.9 & 8.6 \\
11 & 36.4 & 53.6 & 2.1 & 7.9 \\
12 & 43.5 & 47 & 2.1 & 7.4 \\
13 & 18.6 & 73.2 & 1.0 & 7.2 \\
14 & 39.7 & 50.6 & 2.9 & 6.8 \\
\hline
\end{tabular}

The composition of the obtained demulsifiers is presented in Table 3.

As shown in Table 3, the treatment of a fatty acid mixture with isopropanol in an autoclave at elevated temperatures and pressures of 0.8-1.0 $\mathrm{MPa}$ resulted in partial esterification of fatty acids, as was expected. Mainly, the following ethers were found as components of mixtures: isopropyl linoleate, isopropyl linolenate, isopropyl oleate, and isopropyl palmitate.
In general, an increase in the content of ethers in the mixture increases its demulsibility; at the same time, a strict dependence "content of ethers - demulsibility of the mixture" was not found (see Fig. 1).

The correlation coefficient $(r)$ between the content of ethers in demulsifiers and water removal was 0.790; at the same time, with the exclusion of the two most effective demulsifiers from the selection, the correlation coefficient fell to 0.600 . Obviously, fatty acids ethers play 
an important role in the process of removing water from the emulsion. However, the effects of fatty acids (though weaker) on the demulsibility of the mixture cannot be excluded.

As is known, fatty acids themselves are not demulsifiers, unlike fatty acid esters. Therefore, it is interesting that mixture No. 10 showed greater demulsifying ability than No. 8, despite the lower content of fatty acid esters (49.3 vs. $51.4 \%$ ) and a higher content of fatty acids (40.2 vs. $38.1 \%)$. This circumstance can be explained by the synergy of the demulsifying action of mixture No. 10.

A series of experiments were carried out to compare the demulsifier performance of four demulsifiers obtained within this study and a commercial demulsifier, Dissolvan 4411. The same water-in-oil emulsion was used as in previous experiments. Fig. 2 illustrates the dependence of water removal from the emulsion on the coalescence time (from 5 to $30 \mathrm{~min}$ ) for the 5 demulsifiers.

As seen in Fig. 2, commercial demulsifier Dissolvan 4411 showed the best efficiency in comparison to the other samples, which is not surprising. Demulsifiers 8 and 10 demonstrated better performance than the other two (4 and 11).

The effect of demulsifier dosage on the water removal from emulsions is presented in Fig. 3; data are given for mixtures No. 4, 8, 10 and 11.

For all four demulsifiers tested, the maximum water

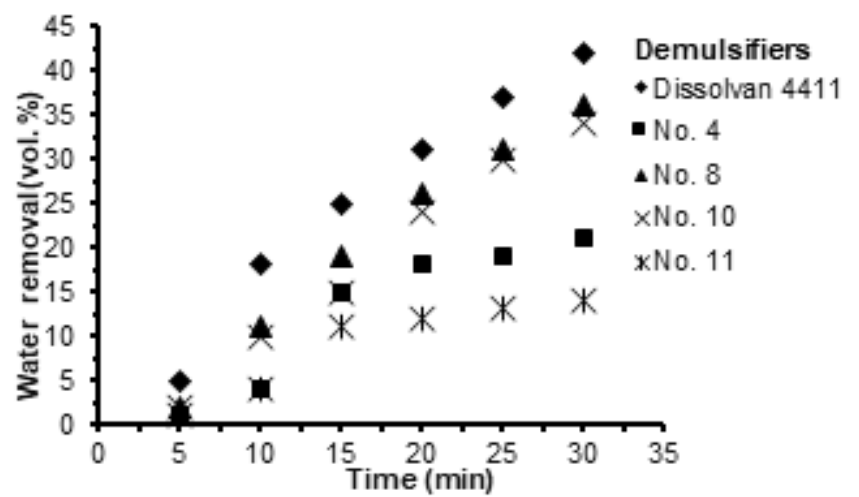

Fig 2. Effect of coalescence time on water removal from the emulsion for different demulsifiers. Water content in emulsion 20 wt.\%; demulsifier dosage 20 ppm; $\mathrm{pH}=7$; temperature $70^{\circ} \mathrm{C}$; time $2 \mathrm{~h}$ removal is achieved at a dosage of $25 \mathrm{ppm}$. Further increase in dosage does not affect the degree of oil dehydration. Moreover, demulsifier 4 demonstrated a slight decrease in water removal, corresponding likely to an emulsification zone. It indicates that dehydration capability of this demulsifier is affected at dosages greater than $25 \mathrm{ppm}$.

For Dissolvan 4411, the water removal was 84 vol. $\%$ at a dosage of $25 \mathrm{ppm}$ (not presented in Fig. 3).

\section{Toluene/Water Dynamic Interfacial Tension}

The ability to reduce the interfacial tension at the oil-water interface is recognized as one of the most important characteristics of demulsifiers [30]. We used

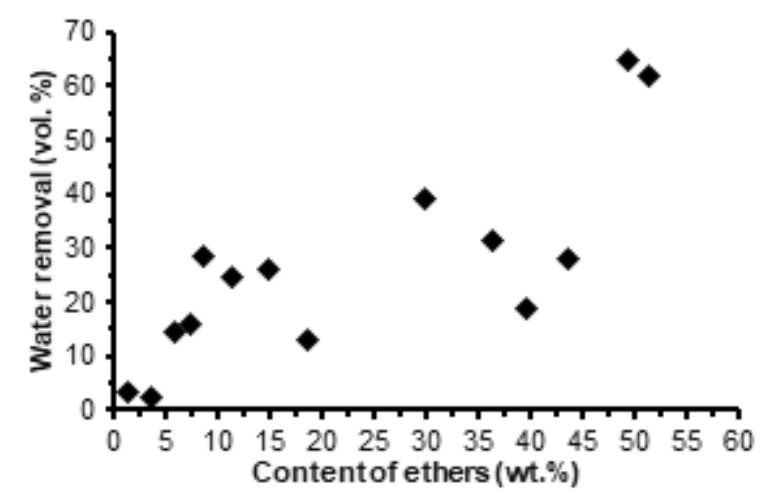

Fig 1. Correlation between the content of ethers in demulsifier and water recovery. Water content in emulsion 20 wt.\%; demulsifier dosage 20 ppm; $\mathrm{pH}=7$; temperature $70^{\circ} \mathrm{C}$; time $2 \mathrm{~h}$

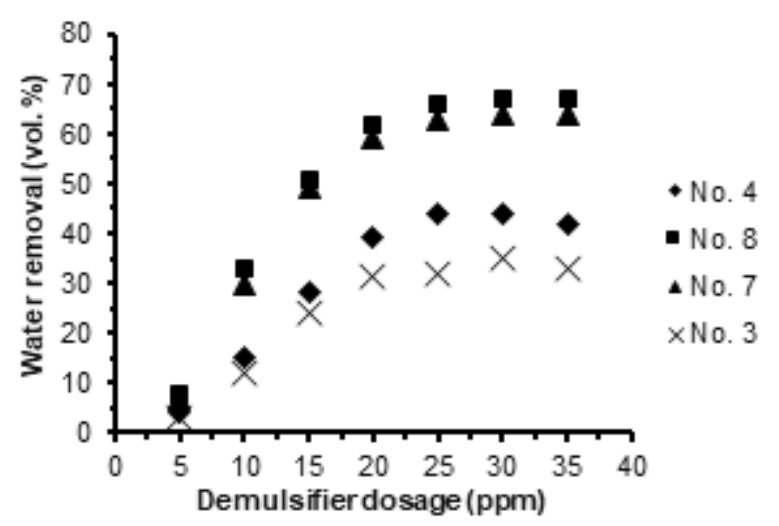

Fig 3. Effect of demulsifier dosage on water removal. Water content in emulsion $20 \mathrm{wt} . \%$; $\mathrm{pH}=7$; temperature $70{ }^{\circ} \mathrm{C}$; time $2 \mathrm{~h}$ 


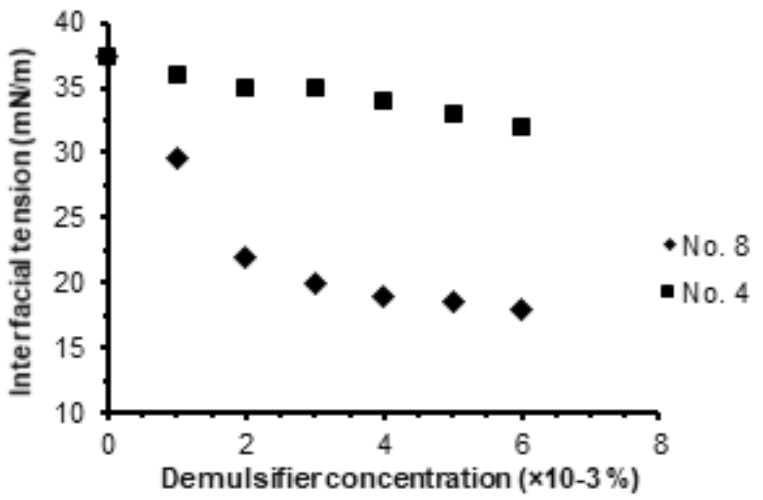

Fig 4. Interfacial tension of demulsifiers No.4 and No. 8 at the toluene-water interface. Temperature $25^{\circ} \mathrm{C} ; \mathrm{pH}=7$

the toluene-water system in our studies since oil from different deposits is different in composition. This circumstance prevents an objective evaluation of the surface-active properties of the demulsifiers tested.

Fig. 4 demonstrates the change of interfacial tension at the toluene-water interface in the presence of different concentrations of the mixtures No.4 and No.8 in toluene, at $\mathrm{pH}=7$.

An increase in the concentration of demulsifier No. 8 in toluene to $0.002 \mathrm{wt} . \%$, sharply reduces the interfacial tension from 37.4 to $22.0 \mathrm{mN} / \mathrm{m}$, which is caused by adsorption of the demulsifier at the toluene-water interface. When the surfactant content in toluene is more than $0.002 \mathrm{wt} . \%$, interfacial tension is reduced much less significantly. This observation is explained by the fact that at sufficiently high concentrations, surfactant molecules cannot settle in the surface layer. The formation of microaggregates, that is, spherical clusters of surfactant molecules, takes place; these microaggregates do not affect the interfacial tension.

Demulsifier No. 4 weakly reduces the interfacial tension in the system under consideration, which is consistent with the ability to remove water from the water-in-oil emulsion (Table 3).

\section{Correlation between RSN and Demulsibility}

$\mathrm{Wu}$ et al. [29] demonstrated the presence of correlation between the RSN of demulsifiers within one family and their dewatering performance. In the present work, the hypothesis of the occurrence of this correlation for the demulsifiers obtained from gossypol resin was

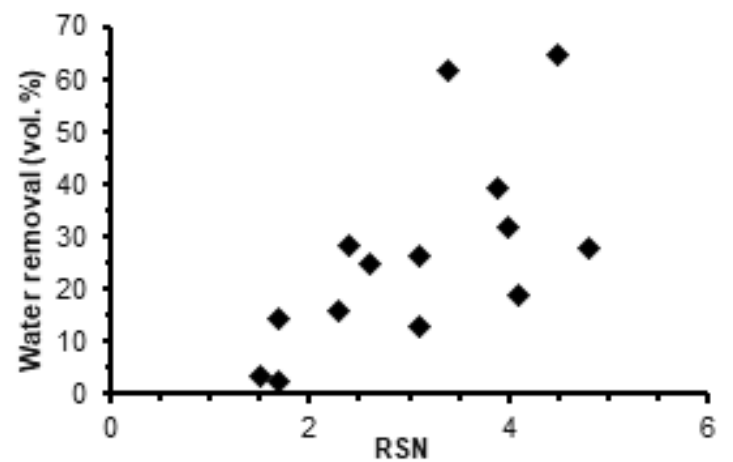

Fig 5. Effect of RSN on water removal from water-in-oil emulsion. Water content in emulsion 20 wt.\%; demulsifier dosage $20 \mathrm{ppm} ; \mathrm{pH}=7$; temperature $70^{\circ} \mathrm{C}$

tested. To ensure a sufficient number of samples, the RSN values were obtained for all demulsifiers, from No. 1 to No. 14.

Fig. 5 demonstrates the dependence of water removal on RSN of demulsifiers; the values of water removal are presented for demulsifier dosage of $20 \mathrm{ppm}$.

As can be seen in Fig. 5, the correlation exists between demulsibility and RSN values, with a correlation coefficient of 0.644 . Generally, increasing the RSN led to an increase in dewatering performance, but there were exceptions. Having exhibited almost the greatest ability to remove water, demulsifier No. 10 had a relatively low RSN.

\section{- CONCLUSION}

By acid-catalyzed esterification of fatty acids, isolated from gossypol resin using isopropanol, 14 mixtures were produced, which were further tested for their demulsifying performance toward water-in-oil emulsions with a water content of $20 \mathrm{wt} . \%$. The correlation between the content of ethers in demulsifiers and water recovery was found to be 0.790 . For four demulsifiers demonstrating the highest demulsifying properties, the maximum water removal (up to $67 \mathrm{vol}$. \% of water) was achieved at a dosage of $25 \mathrm{ppm}$, while the commercial demulsifier Dissolvan 4411 demonstrated $84 \mathrm{vol}$. \% in water removal at the same dosage.

The dependence of water removal on the relative solubility number of demulsifiers was detected for all 14 mixtures, and the correlation coefficient was determined 
to be 0.644 . The highest value of demulsifying performance (64.8\% of water removal at the dosage of $20 \mathrm{ppm}$ ) was observed for the mixture obtained under the following conditions of fatty acids esterification: operating temperature of $385 \mathrm{~K}$, process duration of $4 \mathrm{~h}$, and $\mathrm{H}_{2} \mathrm{SO}_{4} /$ fatty acids mixture ratio of $2.5 \mathrm{wt} . \%$. The results may open opportunities in finding new ways of producing demulsifiers from the waste produced in the process of obtaining edible oils.

\section{- REFERENCES}

[1] Zolfaghari, R., Fakhru'l-Razi, A., Abdullah, L.C., Elnashaie, S.S.E.H., and Pendashteh, A., 2016, Demulsification techniques of water-in-oil and oilin-water emulsions in petroleum industry, Sep. Purif. Technol., 170, 377-407.

[2] Pensini, E., Harbottle, D., Yang, F., Tchoukov, P., Li, Z., Kailey, I., Bahles, J., Masliyah, J., and Xu, Z., 2014, Demulsification mechanism of asphaltene-stabilized water-in-oil emulsions by a polymeric ethylene oxide-propylene oxide demulsifier, Energy Fuels, 28 (11), 6760-6771.

[3] Martínez-Palou, R., Cerón-Camacho, R., Chávez, B., Vallejo, A.A., Villanueva-Negrete, D., Castellanos, J., Karamath, J., Reyes, J., and Aburto, J., 2013, Demulsification of heavy crude oil-in-water emulsions: A comparative study between microwave and thermal heating, Fuel, 113, 407-414.

[4] Nikkhah, M., Tohidian, T., Rahimpour, M.R., and Jahanmiri, A., 2015, Efficient demulsification of water-in-oil emulsion by a novel nano-titania modified chemical demulsifier, Chem. Eng. Res. Des., 94, 164-172.

[5] Al-Sabagh, A.M., Kandile, N.G., and Noor El-Din, M.R., 2011, Functions of demulsifiers in the petroleum industry, Sep. Sci. Technol., 46 (7), 1144-1163.

[6] Liang, J., Du, N., Song, S., and Hou, W., 2015, Magnetic demulsification of diluted crude oil-inwater nanoemulsions using oleic acid-coated magnetite nanoparticles, Colloids Surf., A, 466, 197202.

[7] Liu, J., Li, X., Jia, W., Li, Z., Zhao, Y., and Ren, S., 2015, Demulsification of crude oil-in-water emulsions driven by graphene oxide nanosheets, Energy Fuels, 29 (7), 4644-4653.

[8] Razi, M., Rahimpour, M.R., Jahanmiri, A., and Azad, F., 2011, Effect of a different formulation of demulsifiers on the efficiency of chemical demulsification of heavy crude oil, J. Chem. Eng. Data, 56 (6), 2936-2945.

[9] Chen, Y., Lin, X., Liu, N., Cao, Y., Lu, F., Xu, L., and Feng, L., 2015, Magnetically recoverable efficient demulsifier for water-in-oil emulsions, ChemPhysChem, 16 (3), 595-600.

[10] Carneiro, G.F., Silva, R.C., Barbosa, L.L., Freitas, J.C.C., Sad, C.M.S., Tose, L.V., Vaz, B.G., Romão, W., de Castro, E.V.R., Neto, A.C., and Lacerda, V., 2015, Characterisation and selection of demulsifiers for water-in-crude oil emulsions using low-field ${ }^{1} \mathrm{H}$ NMR and ESI-FT-ICR MS, Fuel, 140, 762-769.

[11] Nguyen, D., Sadeghi, N., and Houston, C., 2012, Chemical interactions and demulsifier characteristics for enhanced oil recovery applications, Energy Fuels, 26 (5), 2742-2750.

[12] Song, X., Shi, P., Duan, M., Fang, S., and Ma, Y., 2015, Investigation of demulsification efficiency in water-in-crude oil emulsions using dissipative particle dynamics, RSC Adv., 5 (77), 62971-62981.

[13] Cao, Y., Chen, Y., Liu, N., Lin, X., Feng, L., and Wei, Y., 2014, Mussel-inspired chemistry and Stöber method for highly stabilized water-in-oil emulsions separation, J. Mater. Chem. A, 2 (48), 20439-20443.

[14] Liu, J., Wang, H., Li, X., Jia, W., Zhao, Y., and Ren, S., 2017, Recyclable magnetic graphene oxide for rapid and efficient demulsification of crude oil-inwater emulsion, Fuel, 189, 79-87.

[15] Chen, Z., Peng, J., Ge, L., and Xu, Z., 2015, Demulsifying water-in-oil emulsions by ethyl cellulose demulsifiers studied using focused beam reflectance measurement, Chem. Eng. Sci., 130, 254-263.

[16] Huang, X.F., Li, M.X., Lu, L.J., Yang, S., and Liu, J., 2012, Relationship of cell-wall bound fatty acids and the demulsification efficiency of demulsifying bacteria Alcaligenes sp. S-XJ-1 cultured with vegetable oils, Bioresour. Technol., 104, 530-536. 
[17] Qu, G., Gong, X., and Liu, Y., 2014, New research progress of the demulsification of produced liquid by polymer flooding, J. Chem. Pharm. Res., 6 (1), 634640.

[18] Lee, W.S., Chua, A.S.M., Yeoh, H.K., and Ngoh, G.C., 2014, A review of the production and applications of waste-derived volatile fatty acids, Chem. Eng. J., 235, 83-99.

[19] Liang, J., Li, H., Yan, J., and Hou, W., 2014, Demulsification of oleic-acid-coated magnetite nanoparticles for cyclohexane-in-water nanoemulsions, Energy Fuels, 28 (9), 6172-6178.

[20] Toba, M., Abe, Y., Kuramochi, H., Osako, M., Mochizuki, T., and Yoshimura, Y., 2011, Hydrodeoxygenation of waste vegetable oil over sulfide catalysts, Catal. Today, 164 (1), 533-537.

[21] Ramos, M.J., Fernández, C.M., Casas, A., Rodríguez, L., and Pérez, Á., 2009, Influence of fatty acid composition of raw materials on biodiesel properties, Bioresour. Technol., 100 (1), 261-268.

[22] Desroches, M., Escouvois, M., Auvergne, R., Caillol, S., and Boutevin, B., 2012, From vegetable oils to polyurethanes: Synthetic routes to polyols and main industrial products, Polym. Rev., 52 (1), 38-79.

[23] Chen, L., Liu, T., Zhang, W., Chen, X., and Wang, J., 2012, Biodiesel production from algae oil high in free fatty acids by two-step catalytic conversion, Bioresour. Technol., 111, 208-214.

[24] Li, Y., Zhang, X., and Sun, L., 2010, Fatty acid methyl esters from soapstocks with potential use as biodiesel, Energy Convers. Manage., 51 (11), 2307-2311.

[25] Nadirov, K.S., Zhantasov, M.K., Sakybayev, B.A., Orynbasarov, A.K., Bimbetova, G.Zh., Sadyrbayeva,
A.S., Kolesnikov A.S., Ashirbayev H.A., Zhantasova D.M., and Tuleuov, A.M., 2017, The study of the gossypol resin impact on adhesive properties of the intermediate layer of the pipeline three-layer rust protection coating, Int. J. Adhes. Adhes., 78, 195199.

[26] Nadirov, K.S., Zhantasov, M.K., Bimbetova, G.Zh., Kolesnikov, A.S., Sadyrbayeva, A.S., Orynbasarov, A.K., Kutzhanova A.N., Turemuratov A.S., Botabaev N.E., and Zhantasova, D.M., 2016, Examination of optimal parameters of oxyethylation of fatty acids with a view to obtaining demulsifiers for deliquefaction in the system of skimming and treatment of oil. A method to obtain demulsifier from fatty acids, Chim. Oggi, 34, 72-77.

[27] Sendzikiene, E., Makareviciene, V., Janulis, P., and Kitrys, S., 2004, Kinetics of free fatty acids esterification with methanol in the production of biodiesel fuel, Eur. J. Lipid Sci. Technol., 106 (12), 831-836.

[28] Márquez, N., Antón, R.E., Graciaa, A., Lachaise, J., and Salager, J.L., 1998, Partitioning of ethoxylated alkylphenol surfactants in microemulsion-oil-water systems. Part II: Influence of hydrophobe branching, Colloids Surf., A, 131 (1-3), 45-49.

[29] Wu, J., Xu, Y., Dabros, T., and Hamza, H., 2003, Effect of demulsifier properties on destabilization of water-in-oil emulsion, Energy Fuels, 17 (6), 15541559.

[30] Krawczyk, M.A., Wasan, D.T., and Shetty, C., 1991, Chemical demulsification of petroleum emulsions using oil-soluble demulsifiers, Ind. Eng. Chem. Res., 30 (2), 367-375. 